\title{
Make/Use: a system for open source, user-modifiable, zero waste fashion practice
}

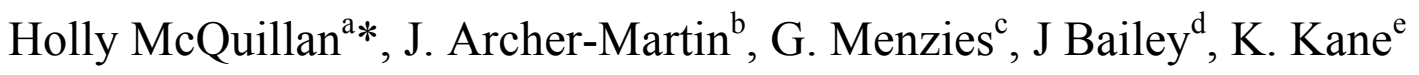 \\ and E. Fox Derwin .
}

${ }^{a}$ Swedish School of Textiles, Hogskolan Borås, Borås, Sweden; ${ }^{b-f}$ School of Design, Massey University, Wellington, New Zealand

holly.mcquillan@hb.se

Holly McQuillan is a designer, writer and facilitator, who works primarily in the field of sustainable design practice. Holly is a leader the field of Zero Waste Fashion, curating and designing for exhibits of contemporary zero waste fashion design practice, and is co-author of Zero Waste Fashion Design (2016). Currently she a PhD student at the Swedish School of Textiles.

Jen Archer-Martin is a spatial designer, lecturer and researcher at Massey University, Wellington. Her collaborative, interdisciplinary design practice seeks to facilitate temporary installations, events, performances and exhibitions, with experience in residential architecture and commercial interior design.

Greta Menzies is a Wellington based artist/designer, who recently completed her MDes and is currently a freelance designer. Her work considers the transformational and performative possibilities of bodies and clothing. Future thinking and a concern for sustainable practice inform her work.

Jo Bailey is a lecturer and designer at Massey University School of Design in Wellington. She's interested in facilitating access to information through design, whatever format or form that takes. With a former-life degree in Geography, she has a strong interest in the environment and conservation. She believes in making things as simple as they can be, but not simpler.

Karl Kane's research focuses on service, experience and social design, civic participation and brand communication. His research interests primarily sit within the area of 21 st Century Citizenship. He teaches in the visual communication degree and consults/mentors within Massey University's Open Lab, with a focus on service, experience and social design. As an Industrial Design lecturer and product designer, Emma Fox Derwin's practice concentrates on furniture design targeting new cross-disciplinary approaches to flat-pack 
furniture design through new materials and construction methods. Her work pushes the boundaries of furniture design through functional designs that both challenge the way we relate to and use the objects in our daily lives.

This work was supported funding from the Massey University Research Fund, College of Creative Arts Strategic Research Fund and Objectspace Gallery. 


\title{
Make/Use: a system for open source, user-modifiable, zero waste fashion practice
}

\author{
This paper discusses Make/Use, a multi-disciplinary research project exploring \\ 'User Modifiable Zero Waste Fashion'. In particular, it addresses the use of \\ textile print and a parametric matrix to facilitate the cognitive and creative \\ processes involved in the transformation from two-dimensional to three- \\ dimensional form. The Make/Use project centres on the development and testing \\ of an embedded navigational system by which users can formulate a functional \\ understanding of the form and construction of a garment and its opportunities for \\ manipulation. It questions how the encoding of navigational clues and markers \\ into a garment might aid in its facility for creation and modification by the user, \\ aiming to enhance emotional investment and connection, and extending its \\ functional life by providing embedded opportunities for alteration and visible \\ repair.
}

Keywords: zero waste fashion; textile print; wayshowing; use practice; open source, matrix.

\section{Introduction}

This paper discusses 'Make/Use', a multi-disciplinary research project exploring 'User Modifiable Zero Waste Fashion' (UMZWF): garments that can be made and modified by users, with no fabric waste. Exploring what occurs if we consider the aesthetic of the garments we wear and how we make and use them, Make/Use responds to the crisis of waste in today's fashion industry. The project builds on Holly McQuillan's 'Zero Waste Fashion' (ZWF) research, questioning industry conventions in relation to knowledgekeeping, production, and consumption. To date, Make/Use has undergone two key phases. McQuillan developed 'MakeUse v1' through involvement in 'Local Wisdom', part of Dr. Kate Fletcher's 'Craft of Use' project (Fletcher \& Toth-Fejel, 2014). Curious about the intersection of ZWF design and 'use practice' (the ways in which people use their clothes), McQuillan imagined a fashion industry of both experts and non-experts, 
collaboratively engaged with the sustainable making and ongoing use of garments. To further the positive impact of ZWF by reducing material waste in both production and use, she hypothesized that the lifespan of garments could be lengthened by enhancing the garment-user connection through processes of making and modifying. This paper discusses 'Make/Use v2', in particular the development of an 'embedded wayshowing system' that encodes navigational markers into the textile print of the fabric, and the discovery of a 'zero waste matrix' that underpins the relationship between garment form and fabric width for Make/Use garments. Findings from these interconnected lines of enquiry establish a platform for further innovation in UMZWF systems.

The embedded wayshowing system is the original focus of Make/Use, and attempts to exploit the direct relationship between fabric, textile print and garment form in zero waste construction. In ZWF none of the fabric is lost as waste, which allows for alternative design and modification options to be built into a single garment pattern as layered cut lines, printed directly onto the fabric. Because the fabric is retained, the garment form is open and can be re-set (mended), re-cut and re-made using different cut lines ${ }^{\mathrm{i}}$. Make/Use $v 1$ tested embedding the modifiable garment pattern and the instructions for its use into the textile print design. Both pattern and guide, the print aimed to facilitate the cognitive and creative processes involved in the interpretation of a two-dimensional garment pattern and its transformation into a three-dimensional garment form. Makers were aided in gaining a functional understanding of the construction of a zero waste garment, and its opportunities for manipulation, through engaging in the making process. Producing a custom garment from a range of possible options gave them creative agency, with the cut of the garment collaboratively determined between our creative intent and the creative decisions made by the maker during interpretation and construction. This system suggest that the user can adopt a 
mode of active engagement rather than passive consumption, challenging the usergarment relationship. The predominant designer-producer-consumer model of wasteful consumption is shifted to a democratic alternative that engages the wearers of clothes as not just users, but 'maker-users'.

Testing of Make/Use v1 prototypes (Fig. 1) confirmed the viability of digitally printed zero waste fabric patterns ('flats') that could be user-made and modified, but found that for unassisted non-experts, achieving well-constructed garments ('forms') was problematic. Extensive instructions were necessary for uninitiated users to decode the guides within the textile print. Make/Use v2 proposed to remove these barriers to engagement and to develop an open-source system for UMZWF that acknowledged a spectrum of participant skill levels, time and available resources. One barrier identified was the inflexibility of the zero waste pattern, because it is directly tied to the width and length of the fabric. This strand of enquiry uncovered a flexible parametric grid - the zero waste matrix. This matrix can be considered a ZWF garment block ${ }^{\mathrm{ii}}$ that gives the relationship between body measurements and two-dimensional pattern for a particular garment typology. The matrix can be adjusted to suit the interrelated parameters of fabric width/length, size/fit, and garment design variations. Using the matrix as a foundation, it is possible to generate an infinite array of zero waste garment designs. The matrix helps the maker/user to rapidly grasp the underlying geometry and sequence of construction moves needed to transform flat to form. This innovation aims to increase access to ZWF and provide the flexibility required for further uptake in the fashion industry.

The paper reviews relevant literature that locates Make/Use's UMZWF in relation to the fields of ZWF and use practice, and contextualizes the necessity of expanding ZWF research beyond the waste management practices. Key theories are 
introduced around the redistribution of creative agency from the designer to the user, setting up the two platforms by which we seek to democratize fashion production: open design process and product. The development and testing of the Make/Use textile print as embedded wayshowing system is outlined, along with the discovery and subsequent application of the zero waste matrix. Research processes and findings are recounted through a discussion of three user testing scenarios: in-house testing, and two public workshops. While conveyed in a linear fashion, it should be made clear that the research strands acted as interconnected feedback loops, an open process that allowed for the emergence of a new territory for UMZWF exploration.

\section{Review of literature}

\section{Locating the research: User Modifiable Zero Waste Fashion}

Prior to the publication of the first comprehensive book on the subject Zero Waste Fashion Design (Rissanen and McQuillan, 2015), research in the relatively young field of contemporary ZWF design has primarily focused on decoding the actions of the zero waste designer/pattern-cutter to identify modes of working (McQuillan, 2009; McQuillan in Chin, Kim, Hŏ, Chang, \& Prism, 2010; Lumsden, 2010; McQuillan in Adank \& Mehzoud, 2011; McQuillan in Gwilt \& Rissanen, 2011; Townsend \& Mills, 2013; Niinimäki, 2013; Carrico \& Kim, 2014), and the relevance of ZWF to sustainability goals such as timelessness and waste elimination (Rissanen, 2005; McQuillan, Rissanen, \& Roberts, 2013; Niinimaki, 2013). The reduction of material waste in production is central to ZWF. It is estimated that, in 2015, 400 billion square meters of cloth will be made for the apparel industry (Gugnani \& Mishra, 2012), and of this, 60 billion square meters (15\%) will likely be wasted on the cutting room floor. ZWF patterns not only eliminate fabric waste but can reduce the length of fabric 
required $^{\text {iii }}$. However, while ZWF contributes to industry waste reduction, eminent ZWF designer and researcher Timo Rissanen $(2013,160)$ states, “ Zero-waste fashion design is not 'good' in and of itself', going on to say that we need examine the fashion system it exists within as a whole in order to make meaningful change.

In response, Make/Use expands ZWF research to explore how users might engage with zero waste garments. Similarly to Rissanen, Kate Fletcher (with Toth-Fejel, 2014) has speculated that while the average environmental impact of fashion per product may have reduced, the increasing volume of consumption has significantly eroded any gains: approximately 120 billion new garments are made every year. Consumption behavior clearly needs addressing, and one possible avenue is through the transformation of consumers into informed and engaged users. Fletcher (in Fletcher \& Grose, 2012) defines the 'wearing and using of garments' as use practice, and positions it as central to the practice of garment design. Fletcher's exploration of the craft of use of clothing encourages designers to learn from the ways in which users 'mitigate... intensify, and adapt' clothing to suit their lives. With the exception of Rissanen's Endurance Shirt (2014) which explored ongoing repair in zero waste menswear, the craft of use of ZWF has not previously been explored, and forms the research agenda of Make/Use.

\section{Locating the agency: designers as facilitators, users as makers}

Fletcher's notion of use practice challenges the existing ZWF literature, as it shifts the creative agency from the expert designer or craftsperson to the everyday clothing user, reframing use practice as a 'craft' in its own right. This subsequently throws into question the role of design and the designer, in relation to the role of the user, the design process and resulting product. Manzini’s 1994 call to arms, Design, Environment and Social Quality: From 'existenzminimum' to 'quality maximum', questions designs role 
in a world in crisis. He calls for designers to act within three proposed consumption scenarios $(1994,40)$ : transforming from consumption of products to 'Care', 'Utilization of Service', and 'Non-Consumption'. Design behavior, activated through these lenses, aims to instigate 'a new way of behaving or of viewing the world'. In order to expand the 'vision for fashion design' to engender behavioral change around 'the consumption, wearing and using of garments', and subsequent systemic change in 'the systems in which the wearing and using occurs' (Rissanen, 2013, 160), we need to shift the role of design from the creation of products to the facilitation of social and political change.

The fashion industry is currently built around ideas of the designer as expert; the keeper of specialist knowledge that informs a creative practice. Design students are often presented with visions of the fashion designer as "somewhere between rock star and artist, designing mainly with a sketchbook and directing a group of able production people" (Blomfield \& Trade, 2002). While other fields have moved beyond this mentality the fashion industry largely remains locked in a 20th century understanding of the role of the designer. In his 1990 book Technocracy and the Politics of Expertise, Frank Fischer describes “...the ways in which expert knowledge and technocratic practices have become key political resources sustaining increasingly undemocratic forms of decision-making” ('Review: Technocracy and the Politics of Expertise', 1992). According to Torgerson (1992) Fischer proposes "a radical democratic alternative which would wed expertise with an active public". While Fletcher's craft of use engages with this 'active public' and poses an alternative to Blomfield's technocratic 'designer as rock star' model, it leaves room to explore more democratic relationship between expert and user. 


\section{Democratizing the design process: tools and facilitation}

Democratization of the design process hinges on the redistribution of design knowledge and creative agency. In order to move from a technocratic to a democratic model of design, the notion of creativity must be explored from the perspective of the user. Liz Sanders (Sanders \& Stappers, 2008, 12) observes Four Levels of Creativity: doing, adapting, making and creating. Ranging from wanting to 'get something done' to the more explorative aim of expressing creativity, of importance is that 'expertise, interest/passion, effort and returns grow with each level'. Through this desire for creativity in ordinary life, users can become part of the design team, but "they must be given appropriate tools for expressing themselves" $(2008,12)$. This echoes the wedding of expertise and active public proposed by Fischer, suggesting that the role of the designer in transforming the passive consumer into an active participant in the design process is one of facilitation and scaffolding through the provision of cognitive tools.

Matt Ratto (2011) proposes critical making as a hinge between a conventional model of designer, maker and user, and an understanding of the designer-as-maker, or user-as-maker. He states that critical making focuses "on making practices themselves as processes of material and conceptual exploration... it is the making experience that must be shared." The sharing of the action, knowledge and tools of the making process opens the way for a more democratic creative process, allowing the user to actively create 'novel understandings'. The exploration of the intersection between craft of use and ZWF design redefines the roles of designer, producer and consumer, sharing the making process by repositioning the consumer as both maker and user, and empowering them with creative agency. Both Sanders and Fischer propose a need for tools that scaffold this experience, enabling it to generate new understandings and engender new modes of behaviour. 


\section{Open design: unfinished things and wayshowing as an open system}

Cameron Tonkinwise (2005), in Is Design Finished?, suggests that we need to reframe design entirely and stop designing mere 'things'. Instead, we should be designing 'how things thing'. He issues the challenge that we "design timely things, things that can last longer by being able to change over time" or that we design unfinished things, "things in motion"(Tonkinwise, 2005, 6).

The proposal to design unfinished products is further explored by Fuad-Luke in 'Ways of Making' $((2009,95)$ which target the over-consumer. According to Chapman (2005), stories help develop the desire to hold onto things; a notion that was tested by Fuad-Luke and Anya Herscher in a fashion context in Half Way (in Niinimaki, 2013). Half Way Products are produced incomplete for finishing by the consumer, where mistakes become part of the narrative of making and owning. Workshop participants determine their level of skill and involvement and are supported to modify, make or design a prepared garment style ${ }^{\mathrm{iv}}$. This approach transforms a passive relationship between the consumer and ready-to-wear garment into one where the consumer becomes active in the design and making of their garments. Another example of open garment design is the Post-Couture project (van Strien, n.d.). Targeted at a non-fashionspecific 'maker culture', their approach simplifies the making of a garment so that it requires no stitching, and provides the garment files for download and production at a 'maker-space' anywhere in the world. Aimed at democratizing the making process, it does not open the design of the garments to ordinary users.

A building or city can be seen as something activated by the user or inhabitant. 'Wayshowing', a system of design elements that facilitate 'wayfinding', is "the process of using spatial and environmental information to navigate to a destination" (Lidwell, Holden, \& Butler, 2003, 260). Per Mollerup's (2006) Wayshowing: A Guide to Environmental Signage clarifies the relationship between wayshowing as design output, 
and wayfinding as intended user experience. In this manner, wayshowing can be considered an open system that is designed to be interpreted or completed by the user. The term wayfinding is most commonly associated with the disciplines of urban planning, architecture and landscape design, and their intersections with visual communication design. Popularized by Kevin Lynch's (1960) in The Image of the City, this was expanded by Romedi Passini (1984) in Wayfinding in Architecture. Lynch (1960) describes the process of finding one's way as having four phases: orientation, route decision, route monitoring, and destination recognition, while spatial cognition is aided by five key elements: paths, districts, edges, nodes and landmarks. When successfully laid out and comprehended, these facilitate the legibility of a city, or "the ease with which its parts can be recognized and ... organized into a coherent pattern" (Lynch, 1960, 2). In attempting to develop an open design system, we explored the application of spatial wayfinding to the process of garment transformation, attempting to translate Lynch's city-image to one of garment-image, whereby the garment parts can be easily recognized and organized. Wayshowing/finding is generally considered in an environmental rather than object-based context, so this may seem somewhat of a leap, but as suggested by creative pattern cutter Julian Roberts (2013), a garment can be considered a space for the body to pass through. Rather than merely transposing the concept of wayshowing onto the creation of garment-as-object, the research shifts toward this notion of garment-as-space. This reveals a new, transdisciplinary, understanding of the zero waste garment that underpins Make/Use v2.Discussion of research

\section{Overview}

The Make/Use v2 research outlined below was conducted through a period of in-house testing and development, followed by test workshops with volunteer participants. This 
shaped the format of a series of public workshops, first delivered as part of a monthlong exhibition and residency at Objectspace Gallery in Auckland, New Zealand, and since, at various locations worldwide ${ }^{\mathrm{v}}$. While the intent was to develop a series of standalone UMZWF patterns that could be openly shared with users, it became clear that we needed to design both the system, and the means for understanding and disseminating it. The discussion is structured around three such participatory experiences: an initial inhouse test is used to set up the basic concepts and problems with using the printed pattern to create the garment form, the 'Flat-to-Form' workshop illustrates the use of the embedded wayshowing system, and the 'Your Style' workshop helps to demonstrate the further potential of the customizable zero waste matrix.

The collection of Make/Use v2 prototype garments and patterns consists of seven garment forms: Crop Tshirt, Long Tshirt, Long Coat, Wrap Dress, Tube Dress, Skirt and Trousers ${ }^{\mathrm{vi}}$. The concepts that enable making/using are most easily illustrated in the Crop Tshirt (Fig. 2) ${ }^{\mathrm{vii}}$. The foundational garment used to develop the Make/Use systems, it provides a relatively low level of complexity and a recognizable garment typology. The pattern is derived from a minimal waste pattern often referred to as the Bog Coat, that can be traced back to at least the Danish Bronze age (Burnham, 1973). It has been explored by numerous historians and designers over time (ibid., Tilke, 1922; Balenciaga, 1961; Telfer, 2008; Rissanen, 2013; McQuillan, 2014), because of its simplicity, efficiency and versatility. The basic modifiable Make/Use t-shirt pattern was developed through Make/Use $v 1$ and $v 2$. Beyond creating the basic t-shirt form, embedded in this pattern are four possible groups of modifications (Fig. 3). In combination with three choices of neckline offered, the options embedded within the Make/Use Crop Tshirt create 48 possible permutations from a single pattern ${ }^{\text {viii }}$. This pattern became the testing-site for the embedded wayshowing system, and was the site 
of discovery of the underlying parametric system that developed into the zero waste matrix.

\section{Initial 'in-house' workshopping}

User testing of the textile print as navigational system in MakeUse $v 1$ revealed its complexity and the need for either verbal explanation or a key to decode the instructional print elements ${ }^{\mathrm{ix}}$. Most elements referred to a corresponding action, such as 'cut and separate' or 'cut and fold back' (Fig. 4). One example referred to a means of orientation: a 'guide' line, indicating center front or back of the garment. Upon analysis, a lack of consistency in the visual instructions was noted, as was a lack of hierarchy. These early tests suggested the potential of the embedded instruction concept, and a need for further development, both in terms of its functionality and legibility as a system, and its aesthetic as a textile print.

Initial Make/Use $v 2$ testing further explored the use of coded cut lines and matching symbols as clues to the 'completion' of the garment. These in-team tests involved the garment-form designer presenting two other team members with a paper prototype of the Crop Tshirt pattern, with no instruction. Despite having knowledge of the basic pattern and modification concepts and being proficient in three dimensional form design, they were unable to successfully transform the paper 'flat' into the intended garment 'form' without additional guidance. An example of feedback loops and 'fast failure', this test highlighted the existence of a procedural hierarchy which had not previously been visible to the ZWF expert due to it being innately, rather than explicitly, understood. This prompted a search for visual hierarchy to communicate multiple levels of instruction within the textile print, as well as attempts to clarify and articulate the underlying geometric logic. 
Subsequent tests looked to find a coherent synthesis between the existing visual languages of cartography and pattern-making. Issues arose with the inherent incompatibility of coded systems that have been developed over time within specialist disciplinary fields. This may be exemplified by the dashed line, which could be variously interpreted by the different specialists as a seam, fold, cut, perforation, grid line, route, or the delineation of an object 'behind' or 'above'. While attempting to use different line types, weights and colors to denote all of the instructions required in one pattern to create multiple possible garment forms ${ }^{\mathrm{x}}$, it became clear that the inherent complexity of this codification still required either verbal explanation or a key. This was considered a failure to liberate the creative act from overly-coded technocratic understanding. It became clear that what was required was not simply a set of instructions for making, but a set of cognitive tools for understanding.

In attempting to simplify the navigational system in order to develop these tools, it was realized that the complexity resulted from both the mode of visual communication, and the design of the garment itself, including the number and nature of embedded modifications. This led to an analysis of the pattern design and modification system, clarifying the key volume-creation concept and uncovering a simple underlying organizational system. Secondary paper pattern testing confirmed that these two things helped to cognitively support successful form creation. First, visualizing the basic Tshirt as two conjoined tubes created by joining parallel edges (Fig 5), aided understanding of volume-creation as a simple wrapping from flat plane to cylindrical form. Mapping these 'arm' and 'body' tubes onto the flat fabric reveals the organizational system, a 12zone matrix that anchors the pattern and textile print (Fig 6) relative to both fabric and body 'zones': left or right, front or back, 'sleeve, 'shoulder', and 'body'. 
These findings impacted on both the textile print design and the development of the garment forms themselves, illustrating the interdependence of the embedded wayshowing system and the zero waste matrix. The matrix underpinned the liberation of the textile print from having to communicate complex instructions, allowing the research to explore more open methods of communication that focused on affectively supporting the creative process of the maker/user.

\section{'Make/Use: Flat-to-form'workshop}

With the difficulty of the previous iterations presenting a barrier to the participants in both successful completion of the task, and confidence in doing so, we sought to understand how the textile print might support the creative process both cognitively and emotionally. It was acknowledged that the fear of 'getting it wrong' when decoding complex instructions, implied that the 'right' answer was gate-kept by the designer. In contrast, the intent was to foster an open-ended collaboration between designer, maker/user and textile that empowered the maker/user to actively make design decisions, affording them creative agency. If the designer or expert is not present, this agency hinges on the relationship between the textile and the maker/user. The concept of wayshowing became useful here in the sense that wayshowing is a series of navigational cues or signs left in the landscape for the wayfinder to follow. This prompted the reimagining of the instructional print as an embedded wayshowing system.

Unlike wayfinding at the landscape scale, which may be supported by a map, the zero waste textile is both map (flat) and landscape (form). A proposed shift in focus from print-as-map to textile-as-landscape sought to offer more opportunities for intuitive wayfinding rather than instruction-following. Hiking through a landscape with different levels of perceived navigational information was adopted as a spatial analogy for visual hierarchy. At a basic level, the inexperienced hiker can follow a predefined 
path and signposts. A more seasoned hiker might follow less obvious paths or rely on general orientation and the occasional route marker. An expert might find their own way, able to read less visible cues in the landscape. Within this fabric-landscape analogy it became possible to describe multiple levels of information that existed simultaneously, without having to be immediately visible, or explicitly understood. If not essential to the immediate creative or cognitive process, the information would remain a part of the background print. It was proposed that this system of emergent information might combat the overwhelming experience of deciphering multiple encoded instructions in the textile print.

The resulting wayshowing system borrows from Lynch (1960) and consists of four levels of emergent information - orientational cues, primary paths, secondary paths with supplementary rotational cues, and route markers. In the Make/Use 'Flat to Form' workshop these emergent levels were first explored haptically by making an A4 paper version $^{\mathrm{xi}}$ of the Crop Tshirt (Fig. 7). After being shown a diagram of the Tshirt pattern and the finished garment, participants were invited to create a paper model of the basic Tshirt form from the printed paper. Participants were then able to use primary paths (clearly marked essential cut lines) to begin the form creation process. In the Tshirt pattern, only three essential cuts need to be made: two cuts that separate the fabric of each side of the 'sleeve tube' from the 'body tube', and the neckline (three style options were available). It was found to be helpful to describe the Tshirt as a horizontal tube for the arms/shoulders/upper torso and a vertical tube for the body and to give a brief demonstration of this concept. Two elements in the printed paper pattern further aided in the task. Orientational cues, including recognizable 'landmarks' like the neck hole, and directional marks that suggest the flow of gravity from the high point on the body to lower or outer edges/hems, helped participants to locate the 'body zones' on 
the flat fabric. Once participants located the neckline they were able to cognitively position the body inside the garment, guided by the gravity cues. The research has found that the latter are particularly useful in zero waste pattern cutting, where the various zones of the pattern are contained within the same piece of fabric, but in multiple orientations that can be difficult to understand until they are on the body. This combination of cues helps the maker/user to read the neckline as the high point in the pattern, combating the common tendency to read the uppermost edge as the 'top'.

Once this first stage of volume-creation is successfully completed, participants were introduced to the concept of volume manipulation, central to the Make/Use ZWF pattern cutting methodology. This was achieved through a brief demonstration of the concept, in which a tube cut diagonally and rotated 180 degrees forms a bent tube. Translated into fabric, this creates more volume on one side of the tube, and lifts the hem on the other. In the same way that the delivery of this information was done in stages, the supporting navigational aids in the pattern are given visual hierarchy. Secondary paths, or cut lines for manipulating the volume, are expressed as edges between zones where the background print becomes denser, rather than as clearly marked paths or lines. The rotational movement required to make the modification is supported by the print, with a directional pattern of rotational cues such as chevrons sitting 'behind' the other visual information as a background to the textile print. Participants were not overwhelmed with this information in the first step, as the secondary information is integrated with the background pattern of the print in such a way that it emerged once the participant was ready to focus on it.

Lynch (1960) describes route monitoring as supporting the route-decisionmaking process. This is achieved in the Make/Use textile through the considered placement of visible symbols, or route markers, at points that needed to be connected in 
order to complete the transition to three dimensional garment form. The lineage of these symbols can be traced to pattern-making conventions, and can be seen in proto-typical form in MakeUse v1. The simple symbolic system, devised by the visual communication designers within the team, used basic geometric shapes that require little decoding, and became part of a multi-modal dynamic visual system for the wider Make/Use project. Returning to the spatial analogy of hiking in a landscape, the symbols resemble the route markers placed at intervals along a trail - high-visibility messages of reassurance that one has not gone too far astray. Matching the symbols facilitates the creation of the garment form and provides positive visual feedback that gives the participants confidence that they are 'on the right track', validating their creative decisions.

Participants had varying degrees of success with grasping the basic form creation and customization but quickly learned from each other in the workshop setting, using the wayshowing print as a guide ${ }^{\mathrm{xii}}$. The set of navigational cues that make up the Make/Use embedded wayshowing system act as scaffolding that supports the learning maker-user to explore further as their skill and confidence grows. Forming a layered visual system that takes the raw textile as its base, the cues emerge from the background of the print as required. This open-ended system acts mutually with the maker/user to build their agency, initially shielding them from complexity while gradually unlocking new understandings and more complex garment forms, rewarding those who are ready to look beyond the more basic visual guides. The requirement for explicit guidance decreases as the agency of the maker-user increases and they feel comfortable to ignore the markers and create their own garment forms, leaving the landscape open to affective interpretation. This was demonstrated in the workshop when participants were given a full-size fabric version of the Crop Tshirt to work with. While we anticipated multiple 
variations of the 48 possible garment permutations contained within that pattern, the openness of the system was further illustrated in the unplanned modifications some maker/users chose to make (Fig. 8). The observation was that the participants were afforded the conceptual understanding, confidence and 'permission', not only to do, adapt, or make, but to create (Sanders, 2008).

\section{'Make/Use: Your Style’ workshop}

While user testing of the Make/Use Crop Tshirt showed that the embedded wayshowing system was successful in facilitating cognition and creative agency, it was clear that this success did not occur in isolation. The underlying geometric concepts that were clarified in order to both refine the system and explain how to use it began to emerge as a new way of understanding and teaching zero waste design. It became evident that this was a central innovation rather than a byproduct of the process, leading to the development of the zero waste matrix and a 'grid and template' system (Fig. 9). These were tested through a second workshop typology - 'Your Style' - in which participants could bring their own fabric and customize a Make/Use pattern. In discovering this underlying logic, we found a solution to a key critique of zero waste patterns, which is the lack of flexibility regarding fabric width due to the pattern being directly informed by the size of the piece of fabric. In an industry in which there is no global standard for fabric width, this is problematic. The Make/Use workshop planning encountered the same issue - while fit variations were possible within a single printed pattern, the extent of these was governed by the size of the cloth, meaning that participants desiring a larger fit had to make additional modifications, such as opening the t-shirt at the front to make it a jacket ${ }^{\text {xiii }}$. If participants were to work with different width fabrics, a system was needed to easily adjust the patterns without the expert having to recreate a full custom pattern each time. This redesigning was both unfeasible in the time available, and 
undesirable in that it would place technocratic and creative agency back into the hands of the 'expert', disempowering the maker/user.

The zero waste matrix might best be described as the ZWF equivalent of the fashion 'block'. Conventional blocks are based on a complex matrix that translates the basic 3D garment form, as it relates to the body, onto the 2D plane. Each block corresponds to a specific 'standard' body size, shape and gender. The body is divided into front and back, with joins commonly at the shoulder and side body, creating separate pieces that are then flattened to form the block. This is then used as the base from which to generate patterns for different garment designs. This approach is limited in its consideration for the cloth used, with placement onto the fabric of pattern pieces for various designs differing in the pattern cutting process. In contrast, in ZWF pattern cutting it is the direct relationship between the 'block' or pattern base and the fabric that determines the cut of the garment. While many ZWF designers exploit this relationship to great effect, the challenge of modifying a zero waste pattern to another fabric width or garment fit/size can be difficult for even an experienced pattern cutter. For Make/Use, the need to cater for both novice and expert users amplified the problem. An ideal solution would see the pattern, including embedded modifications, adjustable to suit both different sizes/fits and fabric widths.

The zero waste matrix was utilized during the workshops in two ways. The first was to explain the underlying geometry of the pattern, and aid comprehension of how the different zones of the flat pattern map to the garment form. The second was the development of the 'grid and template' system which formed the main focus of the 'Your Style' workshop. In this workshop, participants began with the same papermodelling exercise as outlined in the first workshop. It was found that starting in this small-scale and informal way reduced the trepidation about cutting into cloth, and 
allowed participants to gain confidence and understanding through the benefits of the printed wayshowing system. Rather than an exercise to understand the wayshowing, this became an exercise that used the wayshowing to understand the principles of Make/Use flat-to-form volume creation. Then participants were instructed in how to adapt their own grid using custom parameters. While in this workshop the participants were able to choose to make any garment from the full Make/Use collection, the Crop Tshirt will again be employed here to illustrate the properties of the matrix and the generation of a custom grid and garment pattern.

The 12 zones of the t-shirt pattern are defined by a $4 \times 3 \operatorname{grid}^{\mathrm{xiv}}$. In its simplest form, four equal sections across the width of the fabric relate to the garment/body circumference (equal to full fabric width) and sleeve length (equal to a quarter of the width). Of the three vertical sections, the top two are equal and the third variable; the top two rows define the sleeve depth (the top row wrapping backward to form the back of the sleeve and shoulders), and the third, bottom, row makes up the remaining length of the garment (see Fig. 9). The width parameters (fabric width, shoulder width + sleeve length, and body circumference) are thus interrelated, as are the length parameters (fabric length, garment length and sleeve depth) ${ }^{\mathrm{xv}}$. Working backwards, participants were able to measure their desired garment/body circumference to determine their choice of fabric width and the sleeve length relative to their shoulder width, and mark out the vertical divisions on their fabric. How long to cut the fabric was determined by measuring their desired garment length, and adding the desired sleeve depth, then using these dimensions to mark out the horizontal divisions. Participants then had a markedout fabric 'block', customized to their fabric and desired fit, on which to lay out the desired templates. 
The flexible parametric grid is only useful if the pattern can be easily adjusted to fit it. To this end, we separated out each element of the pattern-cutting options into separate templates (Fig. 10). These modular templates were tested in an analogue fashion for the workshops, and are also provided in an open-source digital form. For the Crop Tshirt, six basic template sets existed, each with multiple options: necklines, body rotations, sleeve rotations (elbow), sleeve rotations (shoulder), sleeve-shoulder tapers and sleeve-body tapers. To achieve the most basic garment form, participants selected a neckline and used the corresponding grid intersection to position it, followed by making the three essential cuts (neck hole and sleeve/body separation). Other modifications could be added as desired by locating the templates at the grid intersections. Once marked out and pre-finished ${ }^{\mathrm{xvi}}$, these could then be activated in the initial garment creation, or at a later date. As with the printed textile version of the garments, any cut or modification can always be unstitched and 'reset' in order to select an alternative. This both allows for ongoing adaptability, and relieves some perceived pressure about making the 'best' choice the first time ${ }^{\mathrm{xvii}}$.

The zero waste matrix proved to be a breakthrough innovation, allowing any fabric to be made into any Make/Use garment design with any form variation and modification applied. In the short duration of a standard six hour Make/Use workshop, participants of varying skill levels were able to design and make their own custom versions of the Make/Use UMZWF garments. This has exciting applications beyond the workshops and is already available as an open-source system on www.makeuse.nz, along with the digital print files for the embedded wayshowing system versions. However, a number of limitations remain. One is that the textile print design is not yet adjustable, and so cannot be used in conjunction with the parametric grid. This is an area for further research and development. Another is the recognition that these 
solutions do not fully satisfy the original aim of the research, which was to encode the instructions for garment form creation into the printed textile so that a user could make and modify the garment without supplementary instructions. It is acknowledged that the majority of testing occurred in a workshop setting, where we took the participants through the key concepts and processes, and were there to trouble-shoot. This does not offer a comparable situation to the proposed home user experience, where the user might access the garment patterns or order a digital printed textile through the Make/Use website, and work through the process alone. This is addressed in part by the supplementary material available on the website, which is intended to be further developed and instructional videos added. It is believed that these aids need be introductory only, and that once users understand the basic concepts they are able to find their own way through the textile-as-landscape.

\section{Conclusion}

With the fashion industry in crisis, producing unsustainable volumes of waste, zero waste garment design and construction provides obvious advantages. However, we identify two current key issues with ZWF: its perceived complexity and inaccessibility, and its inability to effect significant change when considered in isolation from consumption and use. Make/Use pursues a re-examination of the goals of ZWF design, extending its application and impact through integrating new understandings of how users might engage with zero waste garments. Borrowing from Fletcher's notion of use practice, we explore how people might make and modify their own zero waste garments, empowering them to engage with both the production and use of their clothing. As demonstrated by Make/Use v1, ZWF garments provide inherent opportunities for ongoing modification due to the whole cloth being retained, giving them the ability to be 'reset' and remade. We initially set out to test whether this process 
could be facilitated by embedding multiple options for making and modifying the zero waste garment, along with codified instructions, into a pattern digitally printed directly onto the fabric. While it was proposed that this would remove the need to translate between conventionally separate elements of fabric, paper pattern, and accompanying instructions, thus simplifying comprehension, user testing revealed that complexity in decoding the various elements of the instructional print remained a central barrier to engagement, despite the overall success of the embedded modification options.

Contrary to the aim of placing creative agency back into the hands of clothing users, this reinforced the perception of ZWF as technocratic.

Aiming to democratize access to ZWF, enhance user connection to the garment and increase both its functional and desirable life span, Make/Use v2 brought together a larger interdisciplinary team to explore how the printed pattern might better support users to understand, make and modify, while simultaneously creating a desirable textile print and garment. Early unsuccessful testing of a symbol-based visual language was revealing: cognitive understanding of the process of transforming the flat pattern into garment form required more than a clever system of 'encoded' instructions. For a start, relying solely on a language of lines and symbols to communicate multiple options and actions made the 'reading' of that language an additional hurdle for the maker/user to overcome rather than reducing the number of cognitive leaps to be made. A better visual hierarchy was needed to guide the maker/user through the stages of the making process. Understanding the garment as a spatial form, the fabric was reconceptualized as both 'map' and 'landscape', and ideas of spatial wayfinding more often applied to cities was used to create a framework for embedding navigational cues. This embedded wayshowing system aimed to support users both cognitively and affectively, reducing intimidating visual complexity and attempting to instead support intuition. The 
development of the Make/Use v2 Tshirt print employed a strategy that turned a simplified logic of volume-creating 'moves' into multiple layers of emergent visual information.

This printed textile was successfully employed in the Make/Use v2 workshops. Participants made essential moves to transform flat to form by following visually obvious primary cut paths, supported by a sense of orientation provided by recognizable landmarks like the neck hole, and directional cues in the print background suggesting how the fabric might fall when orientated to the body. Participants were then enticed and supported to make creative decisions about secondary modifications by looking for less obvious visual cues in the print. A relationship between the maker/user's readiness to look for these cues, and their 'emergence' from the visual field of the print, was observed. Matching symbols/markers provided the reassurance required to start joining edges together to build the garment form. Together, this series of cues both cognitively supported understanding of the flat-to-form transformation, and affectively supported maker/users to feel as though they were 'on the right track'. Furthermore, the openended ambiguity of the print empowered more adventurous participants to re-interpret the options for modification beyond those provided. Rather than all participants reaching the same destination, the resulting variation of emergent garment forms evidenced the openness of the process as a collaboration between designer/facilitator, textile/facilitator and maker/user.

Despite the success of the embedded wayshowing system in facilitating an empowering collaborative encounter with the textile, it was recognized that the textile print was not able to fully remove the need for verbal or other support. Test workshops prompted a rethinking of this system, not as the primary research outcome, but as a tool for supporting initial engagement. With the community of maker/users engaging in 
democratic knowledge-sharing growing, it became apparent that there was a bigger barrier to the democratic application of UMZWF: catering to this diverse community was problematic while the printed textile pattern was still constrained to the dimensions of the cloth. To cater for a variety of participants, sizes, and fabric widths, the system needed to be made more flexible. The Make/Use zero waste matrix emerged as a solution. Translated into a grid and template system, the matrix allowed participants to modify the garment design in relation to the fabric width. In workshop testing, participants successfully created their own grid using custom parameters, then located templates for garment elements onto this grid to create bespoke ZWF patterns, with embedded modification options as desired. Beyond this proof of concept, we believe that this innovation can increase accessibility and flexibility of ZWF for the individual maker/user, regardless of skill level, and pave the way for more widespread uptake of zero waste construction in the fashion industry.

Following successfully prototyping and testing via the Make/Use workshops, both the digitally printed textile with embedded wayshowing system and the customizable grid and template system based off the zero waste matrix have been made publicly available as a set of open-source tools for User Modifiable Zero Waste Fashion. However, research is ongoing. A more comprehensive qualitative study on the empowerment of the maker/user through the wayshowing system, and a quantitative study of the reduction of waste in use through the hypothesized extended life cycle, are required. The grid and template system is currently analogue and lacks the visual support offered by the wayshowing system, while the textile print is not yet flexible. At present the wayshowing print acts as a 'cognitive tool' that enables comprehension of the system, with people then moving on to the more flexible forms possible through the grid and template system. This points to the need for further research and development 
of a digital composite of both systems, whereby the parametric grid locates both garment features and print elements to generate a flexible and comprehensible 'flat' from any width fabric, that can be made into a 'form' for a wide range of bodies. It is at the intersection of these two systems where the research positions new territory for exploration, and forecasts development of a universal system for User Modifiable Zero Waste Fashion design. 


\section{Figure Captions}

Figure 1: Make/Use V1 Cropped Tshirt showing pattern (bottom) and form (top). The digital textile print shown was the first test of textile print as instruction and aesthetic that is explored in Make/Use v2. Photograph by Agnes Lloyd-Platt, Digital file by Holly McQuillan

Figure 2: Make/Use Crop Tshirt print on left and form shown on right. Digital File by Holly McQuillan, Photograph by Bonny Beattie

Figure 3: There are four basic modifications possible from the Make-Use Crop Tshirt print. These are: body volume rotation, armhole volume rotation, sleeve volume rotation and sleeve taper swap. Illustration by Jen Archer-Martin

Figure 4: Make/Use v1 Tube Dress design with key demonstrates early instructional/wayshowing print experimentation. Photograph and illustration by Holly McQuillan

Figure 5: By making three simple cuts, two from either side of the fabric and one cut for the desired neckline the basic tshirt form is able to be created. Illustration by Jen Archer-Martin

Figure 6: 12 zone matrix with body zones mapped onto the surface. This facilitates an understanding of the relationship between 2D fabric and body for the maker/user. Illustration by Holly McQuillan

Figure 7: A A4 scaled paper copy of the textile print was provided to the participants to practice making the garment. Textile Design by Greta Menzies

Figure 8: An example of the variations participants produced from the same tshirt pattern, some followed the guidelines, others deviated from planned modifications (center). Photograph by Bonny Beattie

Figure 9: Make/Use Crop Tshirt grid. This works in tandem with the templates (see Figure 10) to determine placement of the garment design features (such as neckline) at the intersection of the horizontal and vertical guidelines. The guideline placement is 
determined by the users fabric width, body size and designers design outcome. Illustration by Holly McQuillan

Figure 10: Templates for design features shown here are laser cut from recyclable card but can also be printed onto standard A4 or A3 paper if a laser cutter is not available. Both file types are available for download from www.makeuse.nz and include instructions for their use. Photograph by Timo Rissanen

\section{References}

Anon, Cocoon Coat 10/2013 \#103. BurdaStyle. Available at:

http://www.burdastyle.com/pattern_store/patterns/cocoon-coat-102013

[Accessed December 11, 2015a].

Anon, Vintage High Waisted Trousers 04/2015 \#129. BurdaStyle. Available at: http://www.burdastyle.com/pattern_store/patterns/vintage-high-waistedtrousers-042015 [Accessed December 11, 2015b].

Adank, R., \& Mehzoud, S. (2011). Surplus and Creativity: Design and the Readymade. Affect. Retrieved from http://www.affectdesignresearch.com/asset/assets/AffectSite-Contents/PDF-Publications/Surplus-Creativity-Digital.pdf

Balenciaga, C. (1961). One Seam Coat [Garment].

Blomfield, P., \& Trade, N. Z. (2002). The designer fashion industry in New Zealand: A scoping study commissioned by industry New Zealand. Industry New Zealand.

Burnham, D. K. (1973). Cut My Cote (Illustrated). Royal Ontario Museum.

Carrico, M., \& Kim, V. (2014). Expanding zero-waste design practices: a discussion paper. International Journal of Fashion Design, Technology and Education, $7(1), 58-64$.

Chapman, J. (2005). Emotionally durable design: objects, experiences, and empathy. Earthscan.

Chin, K., Kim, Y., Hŏ, C., Chang, N., \& Prism. (2010). 2010 International Fashion Art Biennale in Seoul: war - peace. Sŏul: Korea Fashion \& Culture Association.

Fletcher, K., \& Grose, L. (2012). Fashion and Sustainability: Design for Change. Laurence King Publishers.

Fletcher, K., \& Toth-Fejel, K. (2014). Craft of Use Event. Retrieved from http://issuu.com/sustainablefashion/docs/craft_of_use_event 
Fuad-Luke, A. (2009). Design Activism: beautiful strangeness for a sustainable world. Earthscan Publications Ltd.

Gugnani, A., \& Mishra, A. (2012). Textile \& Apparel Compendium 2012. Technopak.

Gwilt, A., \& Rissanen, T. (2011). Shaping Sustainable Fashion: Changing the Way We Make and Use Clothes. Earthscan Publications Ltd.

Lidwell, W., Holden, K., \& Butler, J. (2003). Universal Principles of Design. Rockport Publishers.

Lumsden, J. (2010). A garment for the upper body with a collar and sleeves and buttons down the front: shirts designed through patternmaking : an essay presented in partial fulfilment of the requirements for the degree of Master of Design at Massey University, Wellington, New Zealand (Thesis). Retrieved from http://turds-mro2.massey.ac.nz:8080/xmlui/handle/10179/2405

Lynch, K. (1960). The Image of the City (1st edition). The MIT Press.

Manzini, E. (1994). Design, Environment and Social Quality: From "Existenzminimum" to "Quality Maximum.” Design Issues, 10(1), 37-43. http://doi.org/10.2307/1511653

McQuillan, H. (2009). Using design practice to negotiate the awkward space between fashion consumption and sustainability. Conference presented at the IFFTI 2009: Fashion and Well-Being?, London College of Fashion.

McQuillan, H. (2014). MakeUse V2: digital textile technology for user modifiable zero waste fashion. Textile and Design Lab and Colab at Auckland University of Technology. Retrieved from http://aut.researchgateway.ac.nz/handle/10292/8560

McQuillan, H., Rissanen, T., \& Roberts, J. (2013). The Cutting Circle: How Making Challenges Design. Research Journal of Textiles and Apparel, 17(1), 39 - 49.

Mollerup, P. (2006). Wayshowing: A Guide to Environmental Signage Principles \& Practices (1 edition). Lars Muller.

Niinimäki, K. (2013). A Renaissance in Material Appreciation: Case Study in Zero Waste Fashion. Journal of Textile Design Research and Practice, 1(1), 77-92.

Niinimaki, K. (Ed.). (2013). Sustainable Fashion - New Approaches. Aalto ARTS Books.

Passini, R. (1984). Wayfinding in architecture. Van Nostrand Reinhold.

Ratto, M. (2011). Critical Making: conceptual and material studies in technology and social life. The Information Society, 27(4), 252-260. 
Review: Technocracy and the Politics of Expertise. (1992). Organisational Studies, 13(3), 488.

Rissanen, T. (2005). From 15\% to 0: Investigating the creation of fashion without the creation of fabric waste. Retrieved February, 5, 2007.

Rissanen, T. I. (2013). Zero-waste fashion design : a study at the intersection of cloth, fashion design and pattern cutting. Retrieved from http://epress.lib.uts.edu.au/research/handle/10453/23384

Roberts, J. (2013). Free Cutting. Julian Roberts. Retrieved from http://www.mediafire.com/view/eabgygf9d0b9ira/FREE-CUTTING-JulianRoberts.pdf

Rudofsky, B. (1947). Are Clothes Modern. Museum of Modern Art.

Sanders, E. B.-N., \& Stappers, P. J. (2008). Co-creation and the new landscapes of design. CoDesign, 4(1), 5-18. http://doi.org/10.1080/15710880701875068

Telfer, D. (2008). Minimal Seam Construction T-shirt. Retrieved September 16, 2015, from http://www.davidtelfer.co.uk/page4.htm

Tilke, M. (1922). Oriental costumes, their designs and colors. Berlin: E. Wasmuth. Retrieved from http://www.indiana.edu/ librcsd/etext/tilke/

Tonkinwise, C. (2005). Is Design Finished?: Dematerialisation and Changing Things. Design Philosophy Papers, 3(2), 99-117.

Torgerson, D. (1992). Reuniting theory and practice. Policy Sciences, 25(2), 211-224. http://doi.org/10.1007/BF00233749

Townsend, K., \& Mills, F. (2013). Mastering zero: how the pursuit of less waste leads to more creative pattern cutting. International Journal of Fashion Design, Technology and Education, 6(2), 104-111.

van Strien, M., Post-Couture. The Post-Couture Collective. Available at: http://www.postcouture.cc/ [Accessed December 11, 2015].

${ }^{\mathrm{i}}$ This concept for zero waste garments has been explored further in a textile context by Greta Menzies' Master of Design thesis “Conversational skins : heirloom 'pelts' that emerge and evolve" (Menzies, 2016). G. Menzies was the textile designer for Make/Use.

ii Also known as a 'sloper' 
iii An unlined coat from Burda patterns (Burda, nd) requires $250 \mathrm{~cm}$ of $150 \mathrm{~cm}$ wide cloth. While the Make/Use Long Coat, with a similar silhouette, requires only $150 \mathrm{~cm}$ of a $155 \mathrm{~cm}$ wide cloth. A pair of trousers from Burda (Burda, nd) requires $230 \mathrm{~cm}$ of $140 \mathrm{~cm}$ wide cloth, while the Make/Use Spiral Trouser of a similar design requires $155 \mathrm{~cm}$ of $150 \mathrm{~cm}$ wide cloth for two pairs, or only $78 \mathrm{~cm}$ of $150 \mathrm{~cm}$ wide cloth if using a reversible fabric.

${ }^{\text {iv }}$ Fuad-Luke also proposes a model of 'Modular Evolved Products' $(2009,101)$ where products are designed to be easily repaired.

v Locations so far include: Dunedin, Wellington and Auckland, NZ; Los Angeles, San Francisco and New York, USA; London, UK; and Borås, Sweden.

${ }^{\text {vi }}$ See supplementary material

${ }^{\text {vii }}$ As in all Make/Use garments, any excess neck or arm hole fabric is retained (featured as a flap or folded back and sewn to the adjacent fabric), allowing for future mending/resetting.

viii Differences in fabric dimensions, placement of cut lines, volume redistribution, neckline and body shaping possibilities, color and textile print, and the potential for maker-users to create their own modifications, allow an infinite number of garment possibilities.

${ }^{\text {ix }}$ We noted other critiques, such as a high degree of difficulty finishing the edges. This was resolved in a range of ways such as painted or pre-embroidered edges through the research. These are not the focus of this paper.

x See Bernard Rodofsky's (1947) Are Clothes Modern, page 146 for an early (1873) example of this approach.

${ }^{x i}$ As a cheap but inflexible proxy to cloth, participants are asked to scrunch up their paper and flatten it a couple of times to soften it so it behaves more like cloth.

xii As with the in-house testing, we found that guidance was needed in explaining the underlying geometry and sequence for a greater success rate. This is discussed in the conclusion

xiii The Make/Use Crop Tshirt for which the wayshowing print was designed will fit only a New Zealand size 8-12.

xiv Seam allowances are not discussed here, but these can be allowed for in the calculations or resolved through alternative edge finishing and joining methods. 
${ }^{x v}$ Adjusting the fabric width will change the body circumference, and shoulder width and sleeve length. Adjusting the fabric length and/or the placement of the upper two divisions will change garment length and sleeve depth.

xvi Prefinishing techniques explored in Make/Use ranged from simple analogue processes to more complex specialty techniques and included digital embroidery, machine sewing, felting and hand painting using latex and house paint.

${ }^{\text {xvii }}$ Assuming the aesthetic impact of resetting is acceptable to the user. 